AGRICULTURE AND BIOLOGY JOURNAL OF NORTH AMERICA

ISSN Print: 2151-7517, ISSN Online: 2151-7525, doi:10.5251/abjna.2012.3.12.493.505

C 2012, ScienceHu $\beta$, http://www.scihub.org/ABJNA

\title{
Dried egg powder utilization, a new frontier in bakery products
}

\section{Ali Asghar and Mudassar Abbas}

\author{
National Institute of Food Science and Technology University of Agriculture Faisalabad, \\ Pakistan
}

\begin{abstract}
Eggs are very nutritious and healthy, both egg white and egg yolk have high biological value. Egg albumen, also called egg white contains a viscous $10 \%$ solution which consists of minerals, peptides and proteins in water. These proteins have high nutritional value for humans due to their specific amino acids composition. In addition, the egg white has specific functional properties in food processing like foaming and stability properties. Major functional properties of whole egg are stability, emulsification, foaming and gelling ability. Whole egg is also applied as colorants. These nutritional properties of egg are applicable in bakery foods, mayonnaise products, salad dressings, confections, ice cream, pastas and many convenience foods. Powdered egg can be used in several preparations during processing of food in place of using liquid egg. Egg powder from spray drying has a better structure as compared to the powder from foam mat drying. Hence, powder from spray drying process can be utilized as an essential ingredient in preparations of cakes, custards, noodles and some of the confectionery products.
\end{abstract}

Key words: whole egg powder, foaming, cake, spray drying

\section{INTRODUCTION:}

Eggs are an excellent source of high quality protein, vitamins and minerals. Humans and animals require protein for building of their structures. For this, we depend upon animal protein and vegetable protein because this makes possible the supply of amino acids which are essential for our body (Weggemans et al., 2001). They offer a balanced distribution of minerals like iron, calcium, phosphorus and potassium. Eggs also have vitamins, particularly vitamin $E$ (tocopherols), vitamin $A$ (retinol), vitamin $B_{12}$ (cyanocobalamine), vitamin $B_{2}$ (riboflavin) and folic acid (Surai and Sparks, 2001). Spray drying produces microencapsulated ingredients of food. Stable emulsions preparation, emulsions atomization and atomized particles dehydration are the basic steps carried out in producing microencapsulated ingredients of eggs. The major components of a spray dryer are an atomizer, air flow and spray drying chamber (Patel et al., 2009). Findings of some researchers related to spray drying of whole egg into powder form have been reviewed here under the following headings.

\section{Outline of the article}

- Nutritional value of an egg

- Whole egg composition

- Technology used to convert egg liquid into egg powder
- Functional properties of egg powder

- Utilization of whole egg powder in bakery Products

Nutritional value of an egg: Eggs are excellent source of high quality protein and one of the best lowprice sources. As we know that dietary protein is utilized by the human body to maintain and build muscular organs and other body organs like nerves, blood and bones. Quality of protein is determined by how effectively the human body can utilize it for growth. It has been revealed that eggs contribute the highest food protein quality known after mother's milk. The FAO of the United Nations, rated the whole egg protein's biological value at 93.7 which is based on a 100-point scale, followed by biological value of cow's milk 84.5, biological value of fish (76), biological value of beef (74.3), biological value of soybeans (72.8), biological value of polished rice (64), biological value of whole wheat (64), corn (60) and biological value of dry beans (58). Amino acids are the building units of protein. Human body can synthesize some amino acids which are referred to as non essential amino acids while other amino acids which human body cannot synthesize are called essential amino acids. Eggs have all nine amino acids which are essential to our body and so called essential amino acids (EAA) including histidine, leucine, lysine, isoleucine, threonine, tryptophan, methionine, phenylalanine, and valine. Because the essential amino acids in egg protein have the same pattern as the pattern of amino acids needed by the 
human body that's why egg is often utilized as a standard of comparison for determining the quality of protein with other foods (AEB, 1999). In addition to this, eggs are very good source of leucine. Leucine is an EAA that increases the energy using ability of muscles and helps muscle recovery after resistance and dynamic exercises; muscles utilize complementary effect between glucose and leucine so men and women doing resistance exercise can have advantage from leucine rich diet. Even more, leucine is an important element in regulation of muscles and synthesis of protein and may be the key amino acids optimizing the skeletal muscle mass by defining increased EAA need (Layman and Rodriguez, 2009).

Eggs contribute little to considerable quantity of all minerals and vitamins which are known to be needed by the human body, excluding vitamin C (AEB, 1999). Eggs are also an excellent source of choline, folate, and selenium, nutrients which are required for normal development of brain (Herron and Fernandez, 2004). An egg has two important parts: the egg white (albumen), and the egg yolk. Both the egg white and the egg yolk contribute essential nutrients to the human body. An average large egg contributes 6.25 $\mathrm{g}$ of high-quality protein based on $10-12.5 \%$ of the Daily Reference Value for protein, and 5 grams of mostly unsaturated fat. Additionally, one large egg also contributes around 200 milligrams of cholesterol (Weggemans et al., 2001); which nearly meets the dietary cholesterol intake limit as established by the American Heart Association at $\leq 300 \mathrm{mg} / \mathrm{d}$; and eggs are not a good source of fiber and carbohydrates (AEB, 1999).

Whole egg composition: Whole egg consists of egg white and egg yolk. Egg white consists of nearly $67 \%$ of an egg's weight of liquid. Major portion of egg albumin is water, contributing about $87.8 \%(\mathrm{w} / \mathrm{w})$; followed by protein, constituting for 9.7 to $10.6 \%$ (w/w); and carbohydrates accounting from 0.5 to 0.6 $\%(w / w)$. Egg albumin contains $56 \%$ of the total protein of egg along with the major portion of the minerals, magnesium, potassium, sodium, riboflavin, chlorine and sulfur in egg (AEB, 1999). Carbohydrates present in egg albumin are either in conjugated with protein or in free form. Glucose of the total carbohydrates in egg albumin accounts for $98 \%$. Additionally, the amount of lipid in egg albumin is $0.01 \%$ which is negligible (Mine, 1995). An average egg white procured from a large egg contributes approximately 17 calories (AEB, 1999).
The egg yolk consists of around $33 \%$ of the liquid egg weight and $44 \%$ of its protein. The egg yolk contains all the fat and cholesterol of an egg. A large egg yolk contributes around 5 grams of fat; of which 1.9 grams are monounsaturated fat, 1.6 grams are saturated fat and 0.7 grams are polyunsaturated fat, in this way egg yolk provides 6 and $8 \%$ of the Daily Reference Values for saturated fat and total fat, respectively. Egg yolk contains all of the cholesterol of the egg. An average whole large egg contributes around 213 milligrams of cholesterol. It has been revealed that increase in dietary cholesterol causes increase in LDL-cholesterol concentrations and serum total, which increase the risks for cardiovascular disease (CVD) of human beings (Howell et al., 1997). Nevertheless, it has been reported that consumption of two eggs in a day had no effect on human health and that consumption of four eggs in a day had only a little effect on cholesterol of human serum (Ginsberg et al., 1994). Egg yolk than does the albumen also contains a higher proportion of vitamins except for riboflavin and niacin. Egg yolk contains a major proportion of vitamins like vitamin $A, D$ and $E$ and minerals like manganese, phosphorus, selenium, calcium, copper, iodine, iron and zinc. Yolk contains more vitamins and minerals than albumin and having 59 calories (AEB, 1999).

Technology used to convert egg liquid into egg powder: Spray drying is a technique used for preserving the liquid foods, by converting it to powder form. The heart of this technology is to spray a feed material which is in liquid form into a hot drying state the temperature of this process ranging from 100 to $300^{\circ} \mathrm{C}$, in which the liquid portion (often water) of the feed material is evaporated. The final resulting product of this spray drying technique is powders in dried, granules or agglomerates form; the shape of the final product depends upon the chemical and physical properties of the feed material, design of the dryer and its operation. Heat and vapor transfer during spray drying process facilitates the evaporation process through the droplets (Schuck et al., 2009).

The whole egg powder obtained by the process of spray dying and freeze drying was subjected to different studies. Whole Egg powders were distributed into three groups. The first group of powders was moisture free, the second group was moisturized to $8 \%$ and the third group of powders was moisturized to $12 \%$ of water content. These samples of egg powders were placed in bags of plastic without venting and stored in darkness for 3 
months at room temperature. The chemical composition including water, proteins and lipid was measured right after moisturizing of egg powders. Similarly cholesterol and oxysterols contents were measured in fresh and stored egg powders. Egg yolk powders have higher water activity than egg white powders. Whole egg powder contains more hydrophilic proteins and less hydrophobic lipids than egg yolk powder. Oxysterol accumulation in egg powder appeared highest with the lowest water activity during storage process; whole egg powders have higher oxysterols accumulation than egg yolk powders similarly spray dried egg powders have high concentration of oxysterols than freezedried powders. Five kinds of oxysterols were determined and identified. In moisture free spraydried whole egg powder following oxysterols are ideentified, 5a,6a-epoxycholesterol $(5 \alpha, 6 \alpha-E P)>7 \alpha$ hydroxycholesterol $\quad(7 \alpha-\mathrm{HC})>5 \beta, 6 \beta-$ epoxycholesterol $(5 \beta, 6 \beta-E P)>7$-ketocholesterol (7$\mathrm{KC})>7 \beta$-hydroxycholesterol $\quad(7 \beta-\mathrm{HC})$. During storage process of egg powder 5,6epoxycholesterols (5,6-EP) were produced in the large quantities (Obara et al., 2006).

High storage stability, good handling and easiness in transportation are shown by Spray dried food powders as compared to liquid food materials (Obón et al., 2009). In the food industry spray drying is commonly used for encapsulation of food ingredients. Many studies have revealed the spray drying process as efficient process to encapsulate food products like flavors, polyunsaturated oils, carotenoids, enzymes, vitamins, minerals and probiotic microorganisms.

The major steps in the microencapsulation technique include stable emulsion preparation which is to be processed; emulsion homogenization; emulsion atomization; and dehydration and evaporation of the atomized particles (Dziezak, 1988), (Shahidi and Wansundra, 1995). During microencapsulation a stable emulsion of fine droplets of the basic material in the wall solution is critical (Kenyon and Anderson, 1988). Therefore, the materials in the wall solution should have characteristics of emulsification as well (Sheu and Roserberg, 1995). Additionally, it is demonstrated that the emulsion rheological properties are most important parameter in the spray drying technique; thus, high viscosity emulsion results in the formation of larger droplets which adversely affects the rate of drying (Drusch, 2007).

The spray drying technology involves:

I. feed concentration before spray drying process;
II. feed atomization to create the favorable conditions for feed evaporation to a dried powdered product having desirable characteristics;

III. in the chamber air-droplet contact, the liquid which is atomized brought in contact with hot gases, which results in $95 \%$ evaporation of the water remained in the droplets within a few seconds;

IV. the drying of droplets and evaporation of moisture takes place in 2 stages, a) rate of evaporation is relatively constant during the first stage and there is sufficient moisture in the drop to replace the liquid evaporated at the surface (Keey and Pham, 1976), and b) the second moisture evaporation stage begins when there is no longer enough moisture to maintain saturated conditions at the droplet surface, causing a dried shell to form at the surface. The rate of evaporation depends on moisture diffusion through the shell, which increases in thickness as the evaporation proceeds. The final step in a conventional spray drying process is

V. Separation stage; in this use of cyclones, bag filters, and electrostatic precipitators are used (Patel et al., 2009).

The most important factor in the regulation of the quality of the product of the spray drying process producing non-hollow particles is the amount of solvent in the product. For hollow particles, both the amount of solvent and particle size is important. Online measurements of the solvent concentration in the product and the mean particle size are very difficult to obtain, this makes the regulation of the product properties especially difficult. Allen et al. (1994) used a cascaded $\mathrm{PI}$ controller strategy to regulate the average particle size for a spray dryer with a pneumatic nozzle atomizer, using on-line measurements of the particle size. The manipulated variable chosen was the nozzle air flow rate. Masters, (1991) discussed three different control schemes and has provided some guidelines for the design of a control system for a general spray dryer. The heating gas flow rate or heating gas temperature is chosen to regulate the amount of solvent that remains in the particle. The application of model predictive controllers to spray dryers is not very common. Christofides, (2002) demonstrated one of the earliest applications of model-based control on a spray pyrolysis process using a population balance model 
of the droplets as the model. The final particle size distribution is controlled using the wall temperature.

Hollow circular particles have many potential applications, but one of the most excellent and important application potential is their application as fillers in syntactic foams. Hollow particles give a means to manufacture light materials of composite (foams) with required thermal, mechanical and electrical properties, due to the small size of the particles they can be easily machined and molded. Hollow particles properties affect syntactic foams properties, most importantly, particles density and their mechanical properties. Mainly three factors affect these properties (Shabde et al., 2005).

- The kind of raw material utilized.

- Particles diameter.

- Skin thickness.

For an obtained particle diameter, the thinner the skin of a particle, the smaller the density of the particle. Thickness and rigidity of the skin also affect the mechanical properties. It is necessary to manufacture reliable and economical particles of micro-hollow polymeric with required properties. Mostly, there are three major methods to manufacture hollow microparticles (Wilcox and Berg, 1994).

\section{Process based on spray-drying \\ 2. Sacrificial core method}

\section{Phase separation and emulsion techniques}

The most highly applied process is based on spraydrying method. In this technology, a polymer solution like particle material is mainly atomized in the chamber of spray drying system. The solution also contains a blowing agent (latent gas), which, as mentioned below, results to the manufacturing of the hollow center. As the small droplets came in contact with the hot air, the evaporation of the solvent occurs, thus forming a periphery of a polymer with higher concentration, at the outer periphery of the droplet. An impermeable layer is shaped as the shrinking of the droplet occurred. The droplet (now a particle) temperature rises upon achievement of evaporation of the solvent, resulting in blowing agent decomposition, trapped in the core of the particle; thus resulting in the formation of the hollow center. The sacrificial core process utilizes cores that are often coated with desirable material. These coated cores are uncovered to the substances that make the cores to liquefy leaving at the rear intact hollow micro-spheres. Even as such technologies give a greater control on the hollow micro-particles geometry, care should be taken to make certain proper coating. Also, these processes are not easily personalized for mass production. The several phase separation techniques to manufacture emulsions that consist of round globules of the desired material, use surface tension forces (Wilcox and Berg, 1994).

A good review of the different aspects associated to hollow micro-spheres can be originated in Bertling et al. (2004). A review of various industrialized methods along with some discussion on the particles characterization and manufacturing process modeling also are provided. Here, the development of a physics-based model for the phenomena associated with an individual particle is discussed. This model can be used to predict the onset of skin formation on the surface of a particle. The literature does not provide a fundamental model that describes the production of hollow micro-particles. A large volume of work has been carried out on the modeling of conventional spray drying operations (formation of non-hollow particles) (Masters, 1991), (Fletcher and Langrish, 2003), mainly as they apply in the food industry. However, these models do not apply to the production of hollow particles because they do not account for the formation of an impermeable skin and generation of gas in the core. When taking into account the production of hollow particles, it is important that the temperatures and concentrations of the individual droplet be determined because spatial variations in the temperatures and concentrations of the droplets are necessary to allow the formation of the outer skin. Thus, the time to skin formation is an important factor in deciding the residence time of the droplets inside the drying chamber, which in turn affects the chamber dimensions.

Farid, (2003) gives a fairly precise model of a single droplet; however within the droplet absorption gradients are absent. A parallel model for a slurry droplet can be established in Cheong et al. (1969). In incineration field, Sirignano, (1999) and his coworkers investigate several conditions throughout the burning of single droplet of fuel. They relate a number of numerical and modeling analysis systems to explain the burning of a single fuel droplet and arrangements of droplets.

In a spray drying system, there are three major phenomena:

\section{Liquid feed atomization}

2. Droplets drying once they are formed 
3. in the spray drying system, motion of the droplet.

The model of spray dryers has remained basically experimental for different reasons, but most important among these is a basic consideration of the atomization process. In common, experimental correlations are dependent upon to explain the atomized spray. Masters, (1991) gives a method for the manufacturing of spray-drying chambers majorly based on experiential know how of the method. Oakley, (2004) and Kieviet, (1997) have attempted to plan spray dryers by means of basic principles. The designs used to explain the spray drying method might contain energy and material balances amid the two phases. The bulk gas phase and droplet phase; or energy and material balances amid these two phases and an explanation of the symmetry between the continuous phases and dispersed phases; or rate based explanations, which do not suppose the existence of symmetry. Energy and mass balances are utilized throughout a preliminary model because their solutions provide specific temperatures and feed rates to attain the desired feature of drying. Ratebased designs are characteristically more complicated and are further divided into classes depending on whether the current of the gas segment is mechanistically modeled or with experimental correlations. The mechanistic rate-based designs to model the heating gas current patterns are precise but usually require complicated computational fluid dynamics (CFD) processes to solve these designs (Fletcher and Langrish, 2003), (Crowe, 1980). In general, the experimental rate-based designs of gas phase are easier to solve, but are reliant on the chamber geometry.

Katta and Gauvin, (1976) explained that rate-based designs that hold empirical correlations to design the gas phase flow can signify the particle phase precisely. However, their work neither explained the hollow particles nor united the entire spray (macroscale) with the droplet (microscale) to get hold of the model parameters. Palencia et al. (2002) presented a mechanistic move towards the spraydryer designing by explaining the spray dryer to be a flow of mixing tanks. In the recent work, the distribution of droplet size is supposed and a representative droplet motion is followed. The droplet trajectory tracking is helpful since this knowledge affects the dimensions of chamber. Modeling the mass and heat-transfer rates between the liquid and the gas phases, and the motion of particle are critical to the model of the spray dryer. In the case of solid particles, it is rational to assume uniform concentrations and temperatures (Oakley, 2004). For instance, Farid, (2003) gives a constant temperature design for formation of crust on a single droplet surface. Similar designs have been suggested by Cheong, (1969) for drying of slurry droplets. When bearing in mind the hollow particles manufacturing, it is significant that the concentrations and temperatures of the individual droplet be explained because spatial differences in the concentrations and temperatures of the droplets are compulsory to allow the outer skin formation. Thus, the skin formation required time is a crucial factor in deciding the droplets residence time within the chamber of drying, which on the other hand affects the dimensions of chamber. In this study, the single droplet design of the phenomena happening on a droplet, urbanized by Shabde et al. (2005), is utilized to investigate the concentration gradients and temperature inside the droplet.

Fed milk replacers which contain formulation of 0,10 or $20 \%$ and crude protein of 0,22 or $44 \%$, as whole egg powder which is spray-dried in a feeding trial of 56-d. Oxytetracycline and neomycin were medicated in milk replacer and was fed from 1-d to 42-d of the experiment in a program of phase-fed. B vitamins, excluding biotin are added in all experimental milk replacers. $1 \mathrm{mg} / \mathrm{kg}$ of supplemental biotin was added in the feed of one half of all calves to measure whether growth is inhibited by the protein avidin in the eggs. A linear reduction in weight of the body, calf starter intake, and efficiency in feed was observed by increased consumption of spray-dried whole egg. During the 56-d trial calves fed milk replacers which contain 0, 10 and $20 \%$ whole egg powder from sparay drying received an average of 486, 369 and 302 grams/day, respectively. Feed utilization efficiency was 446,318 and 231 grams of body weight received per $\mathrm{kg}$ of intake dry matter. Development in body weight and efficiency of feed utilization occurred when calves began to consume calf starter on 29-d. During the trial protein and fat digestibility from egg may have been decreased; however, biotin addition to the milk replacer did not affect performance of an animal, demonstrating that spray-dried whole egg powder avidin was not responsible for reduced performance. The whole egg product from spray drying process utilized in this trial did not contain sufficient nutrients to help adequate growth of calves which were milk-fed (Quigley, 2002).

Both heat sensitive and heat-resistant products can be subjected to spray drying technology, which can 
produce nearly spherical particles of the subjected material. According to Patel et al. (2009), the major components of a spray drying technique include the air flow, the atomizer and the spray drying chamber. Egg industry has become ready for action due to recent advances in technology and commercial standards. The augmentation in requirements and call for providing superior quality food product to consumers at inferior price has been pouring the technological innovations in industries related to egg. For instance, during World War II the overall demand of the food products amplified which led the researchers to take better initiative at that time, which resulted in the improvement of different dehydration methods, especially spray drying method. Yet today, processor's option is spray drying technique which is still very famous for manufacturing good quality whole egg powder (Bergquist, 1995).

Various techniques and measures have been tried to diminish the loss during handling, transportation and storage. One of the most famous methods is to dehydrate the egg. It has countless merits such as condensed volume of the product, stable, longer shelf life and making the product less vulnerable for microbial and enzymatic spoilage because microbes require moisture for their growth and activity. The processes extensively used in the production of dried egg include pan drying, foam-drying, freeze-drying, and spray-drying, the latter being frequently used (Guardiola et al., 1995).

In spite of such a variety of uses and applications, the exact mechanism of spray drying to manufacture particles is not understood completely. One of the reasons for this is that the spray drying technique, characterized by fast, rapid and simultaneous transfer of heat and mass between the heating gas and the solution of feed droplets, is complicated to demonstrate in a mathematical model as several of the model parameters are not easily measurable (Oakley, 2004), (Fletcher and Langrish, 2003).

Such difficulties also minimize the spray dryer operation regulation to tailor the properties of end point like size, density, mechanical, thermal properties of the particles (Masters, 1991). Chambers in spray drying technique are typically vertical vessels with a cylindrical cross section and a conical bottom (Masters, 1991). The size of the conical and cylindrical sections depends on the desirable application needs. Various spray dryer designs can be observed by passing the heating gas either counter-currently or co-currently to the feed solution (Zbicinski and Zietara, 2004)
Atomization: The heart of spray drying process is the atomizer. Dispersing the feed material into very fine particles is one of the key functions of atomizer, in this way surface area of the feed material is increased and material is distributed well within the dryer chamber. The droplets after atomization must not be large enough that produce partially dried powder product, nor so small in size that causes difficulty in recovery of the product. There are several atomizer configurations; however, the most commonly used designs are in the configuration of two fluid nozzles, an ultrasonic nozzle, high-speed rotating disc, airless atomization nozzles and pressure nozzle. Circulation of air within the drying chamber makes a flow which is of well pattern, this avoid the accumulation of incomplete dried powder product on the atomizer or walls. The kind of final product is affected by temperature and air movement of inlet (Ronald, 1997).

In addition to the basic components of spray drying technology, Patel et al. (2009) reported the temperature of inlet air, temperature of outlet air, the feed viscosity, the feed solid contents, the feed surface tension, temperature of feed, nozzle material and solvent volatility as major parameters of spray drying system. Spray drying process is mainly utilized by the food industries. This is an ideal technique where the final product must have some precise and good quality standards like residual moisture content, particle size distribution, and morphology and bulk density. In recent years food powders production by spray drying technique has received more attention due to its controllability and versatility.

Drying and dehydration: Dehydration or drying is one of the oldest and one of the popular methods for preservation purposes. Records indicate that vegetable drying was performed as early as $18^{\text {th }}$ century. Development in drying has been gradual and it addresses issues on industrial requirements. During World War periods (both first and second) the research and development got greater developments because of the greater requirements. Simultaneous heat and mass transfer takes place during dehydration and drying processes, this causes changes in the dried product. Drying and dehydration are often used alternatively without much of difference. But they are not same, according to US Department of Agriculture; dehydrated food cannot have moisture content above $2.5 \%$ on dry basis. But dried food can have moisture content above $2.5 \%$ (dry basis). Different kind of dryers have been developed to address specific requirements such as 
solar drying, drum drying, spray drying, spouted bed drying, fluidized bed drying, microwave drying and freeze drying (Vega-Mercado et al., 2001)

There are several air flow patterns which can be used during this process of spray drying. a) Parallel design or Co-current flow design; in this design, in this spraying of feed material is done into the hot air which enters in the dryer and same direction is being followed by both hot air and the feed material. In this way sensitive dry product exposes to the cooler exit air. b) Counter-current flow: in this spray dryer design, the air and the feed material are introduced at opposite directions of the spray drying chamber, with the top position for atomizer and the bottom for entry of air (Figure.1). In this configuration the product is exposed to hot air, and this configuration evaporates the bounded residual water more effectively than the parallel design; materials sensitive to heat are not subjected to this design (Ronald, 1997).

A liquid droplet is rapidly dried in this process, when it comes into contact with a stream of hot air. The small size of the liquid droplets allows for very rapid drying and the residence time of the material inside the spray dryer is in the order of seconds. The dried material is separated from air in a cyclone separator. The drying rate and the time required for drying

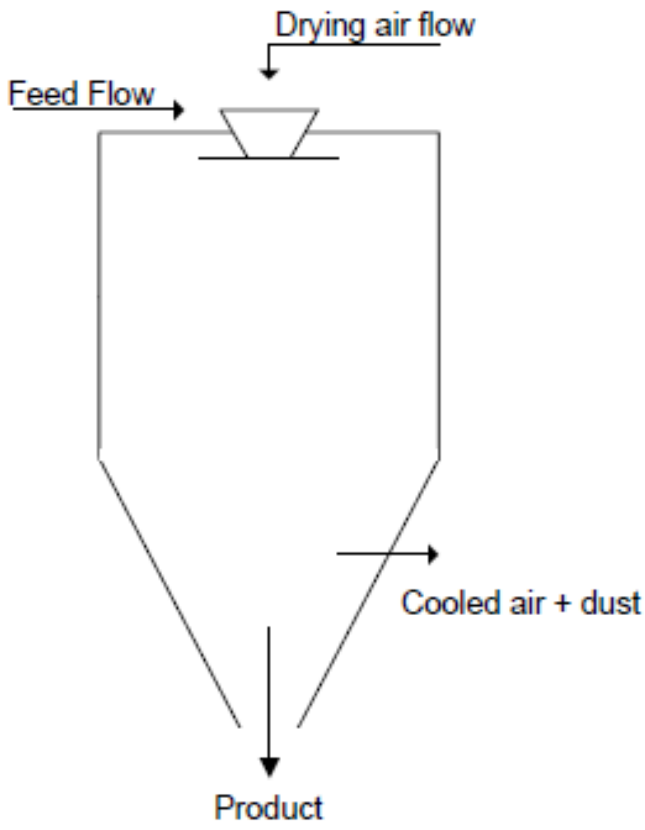

a) depend on the temperature of the droplet being dried (Toledo, 1980). Before spray drying, egg white is allowed to ferment by micro organisms naturally available on the egg shell. Fermentation removes glucose from egg; if glucose is not removed from egg white it can increase the spoilage of egg powder during storage because of enhanced oxidation. It also helps to avoid browning or discoloration by preventing the reaction between glucose and amino groups of protein (Shehab et al., 1978).

In spray drying process atomized stream made contact with a gas stream which had high temperature than the atomized stream, in this way atomized stream was converted into dried product. This elevated temperature of the stream (gas stream) results in the evaporation of liquid contents from the droplets, making small sized particles. In the food industry spray drying technique has been applied exclusively for instance in the manufacturing of powdered milk. Similarly in pharmaceutical industry for pelletization, powders are manufactured (Fletcher and Langrish 2003), (Maa and Prestrelski, 2000), and in agricultural industry to manufacture several granular materials. Recently, the utilization of this technique in manufacturing of micron, sub-micron and hollow particles has also been reported (Shabde, 2005), (Narayan et al., 2001).

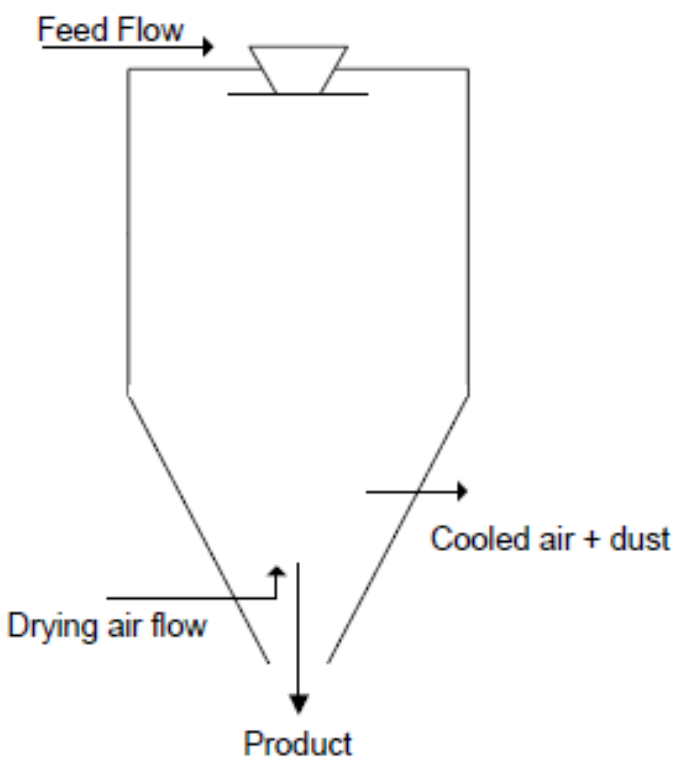

b)

Fig.1. Schematic diagrams of spray drying system 
Functional properties of egg powder: Although it was soon realized that the nutritional value of spray dried whole egg powder protein was not affected by drying procedures. The first drying egg powder acceptability which was produced for over sears armed forces and lend lease from the palatability stand point was decreased and low rapidly with storage time. In addition like fresh eggs the spray dried egg powder did not work properly. The thickening power of egg powder decreased rapidly with aging of the egg powder during formation of sponge cakes. The keeping quality of the spray dried egg powder and its palatability was developed during the whole year by different methods such as gas packing of lower moisture content powder, keeping an eye on the egg drying process and other procedures, if frozen egg is to compete with dried egg powder, the egg powder must have some merits over the frozen egg in some respects this require continuous improvement of dried eggs and versatility in the processes used in forming baked products. One of the excellent quality of egg is its whipping ability which form sponge cakes by foaming, in the early stage of production of dried eggs, the egg powder when reconstituted and whipped at room temperature seldom gave a foam sufficiently stable to produce acceptable sponge cakes (Cora et al., 1947).

Eggs have been called "the cement that holds the cuisine castle together." The yellow portion or yolk is responsible for the emulsifying properties of eggs because it contain fat and lecithin (egg whites do not contain fat). The sensory and physical properties comparisons of many commercial egg alternatives in formulation of food cake were reported. For foaming properties fourteen samples were studied at whipping time of 10 and $20 \mathrm{~min}$ : fish protein, collagen, Solugel collagen hydroysates, Cryogel gelatin, gelatin, whey protein isolate (90\%WPI, 95\% WPI), whey protein concentrate, hydrolyzed whey protein isolate, pea protein, corn zein, casein rice, protein concentrate and soy protein,. However, only 8 samples revealed the potential and were taken forward for further analysis. Only the whey protein isolate alternative was succeeding to maintain a meringue during baking process while the rest of the foams ruptured during the process of baking. The cake formulated with whey protein isolates exhibited a distinctively firmer crumb and crust as compared to the egg albumin control. The volume and height of control cake were also distinctively higher than the egg alternatives. In all sensory categories performed the control cake distinctively outperformed the angel food cake composed with the egg alternative (Mahmoud et al., 2010).

Whole egg powder's flow and water sorption properties with flow conditioners and without flow conditioners were reported. Due to surface modification of the particles, the egg powder flowability improved by the flow conditioner sodium silico-aluminate and silica. Elimination of the hysteresis loop appears due to the addition of these conditioners which improve the flowability. Flow conditioners causes increase in moisture uptake as compared to those without. Spray-dried egg albumin for its gelling and foaming properties is commonly utilized as an ingredient in food products. However, dry-heating egg albumin into powder form can avoid the dangerous effects of spray-drying technique on the properties and functionality of egg white. Several studies have reported and identified steps involved in processing which are responsible for damaging the functional properties of egg albumin, and to evaluate the techniques and processes that could be performed in order to minimize these effects and to mitigate time of dry-heating. Two trials were carried out and the determinations of egg albumin protein conformation and firmness of gel were distinctively different from one to another trail, thus revealing great differentiation in the characteristics of raw material. In spite of this trial effect, steps of processing distinctively modified the foaming properties egg white. The most important damaging step was that of spray-drying which significantly damaged the properties like foaming property. During this spray drying step, transfers of heat and the interface area of air-product rather than rates of shear were responsible for these damages and changes. After this spray drying step, due to stainless steel product interfaces and shear rates, filtering and pumping steps also had a significant damaging effect on foaming property. Contrarily the concentration step had an interestingly improving influence on egg albumin properties like foaming property (Lechevalier et al., 2007).

Whole eggs utilized in the pastry preparation. Indeed, the egg increases in volume during baking process in the oven and during beating. During beating increase in volume is attributed to the egg viscosity, whereas the volume increase in the oven is due to egg proteins coagulation. Eggs are mostly used for their significant functional properties like emulsifying and gelling properties, for their taste and color. Microbiological risks are always there for egg-based 
food products since eggs might contain salmonella and other sporulated microorganisms. Under the conditions of heat treatment proteins of egg usually lose their many functional properties, particularly their ability of gelling, which only can eliminate such salmonella and spores. The main problem is to eliminate microorganisms like salmonella and other bacteria during manufacturing dried-egg products, this elimination requires heat application at high temperatures during pasteurization step to the egg mixture, but such high-temperatures application causes coagulation of the egg. While the process of coagulation is irreversible, once the egg agglomerates the egg product has lost its ability of thickening for other food products. The utilization of decolorized bovine plasma protein as a replacer for egg albumin in white cakes of high yield was studied. Decolorized bovine plasma protein was mixed into cakes at such levels which are comparable to that of egg albumin. Cake batters made from egg whites had higher specific gravities than those cakes made from plasma protein. Cakes made with egg white revealed comparable baked volumes to those cakes made with bovine plasma protein. Cakes made with egg whites had lighter colored crusts and lighter colored crumb than cakes made with plasma protein. Crumb with egg white was less yellow but more green than crumb with plasma protein. Sensory evaluation resulted that cakes made from bovine plasma protein were high in moisture content than those made from egg. Cakes made from bovine plasma protein had an objectionable flavor (Robert and Gail, 1998).

Egg albumins are $88 \%$ water while egg yolks are nearly $50 \%$ water. So contributing liquid to dough and batter is an easy task for eggs. In baking as flour absorbs liquid this causes starch granules to swell forming the specific framework that becomes a muffin, a cookie and a cake. Eventually stream is formed by the conversion of moisture, a leaven so powerful that just one part of liquid ruptures into 1,600 parts of steam. Break into a popover having high ratio of eggs or into a cream puff and their empty centers show a dramatic testimony to the immense power of steam. The steam produced from the liquid part in just one or two eggs shows quietly in most dough and batters to enhance rising in volume, on a smaller scale. The degree of gluten formation within dough is probably the single major effect on biscuit dough theology. Biscuit dough commonly falls into two major categories, hard dough and soft dough. Hard dough due to having protein (gluten) matrix represents the viscous elastic properties which are formed during sheeting and mixing processes. Hard dough requires extensive mixing due to its stiffening and hardening properties due to increase in dough temperature. Except fat and sugar contents that change their viscous elastic properties they are similar to bread dough. Hard dough is commonly sheeted and laminated before stamping and cutting. The developed pieces will generally condense and shrink due to the elastic properties of the gluten. The biscuits may start to shrink in molds during baking process, but become thicker afterwards. This kind of dough composition might also be suited for rotary molded biscuits because of its firm consistency (Hazelton et al., 2004).

While the protein's elastic properties are lost during cooking of eggs, the protein's firming properties allow eggs to perform other functions. As their proteins agglomerate, egg ingredients bind together. Crumbling of meat loaves is less likely and casseroles serve in smaller portions. Crumb coating to a veal cutlet holds more tightly before being rolled in breadcrumbs when it's been dipped in egg. In quiche and crème caramel, proteins of egg unwind and bond to form a mesh like structure that traps cream and milk in a soft gel. While in a crème anglaise or stirred custard, eggs thicken in consistency just as efficiently, but this happen at lower temperatures than cornstarch and flour. Lecithin and some other emulsifiers in yolks of egg come in handy too. Suspension of small fat droplets occurs throughout the emulsions when coated with a thin film of yolk like in hollandaise, mayonnaise and béarnaise emulsions. These distinctive sauces wouldn't be as important, luxurious and as smooth without the egg's emulsifying properties. Egg whites and egg yolks play various functions in making of cake and slight changes in the amount of egg whites and egg yolks will influence the baked cake. For instance, in layer cakes replacement of one whole egg with either two egg yolks or else one and half egg whites to alter the texture of the product. Yolk will produce more flavor able and darker colored cake but having less structure. While egg whites will form a cake softer in texture because egg albumins don't have as much firming properties as egg yolks have. Kinds of fats (shortening, butter, margarine), types of sugars (brown, regular, superfine) and types of flours (cake or all-purpose) used also influence on the properties of cake. When focusing at how consumer's behavior have altered during the past 10 years. Health Focus research reveals that market of consumer has shifted from a largely reactive population trying to protect from health problem a more proactive population organizing daily health and 
managing for a healthier and safer future. Nutrient rich food consumption associated with retarding and preventing several conditions of chronic health is a feasible solution of dietary intake. Egg products have several of such functional nutrients. Besides the highquality of egg protein, other nutrients of egg might be helpful in ensuring good memory and retaining good eye vision. The zeaxanthin and lutein in yolks of egg may help in protecting against age-related macular degeneration and cataracts which is a major cause of blindness condition in older Americans. Scientists also believed that choline of egg yolk helps in proper brain development of infant and capacity of memory throughout the whole life (Morgan and Armstrong, 1992).

Utilization of whole egg powder in bakery Products: According to the EuroAisa Bakery Report 2005, in 2004 the Euro-Asian market for bakery products calculated to 60 million tons, whose approximate worth was 126 billion euro, with retail sales registered exposing an overall increase of $2.5 \%$. The sector of bakery is also a major participant to opportunities for employment and economic growth. In bread-making sector over 120000 enterprises are active only in Europe, of which small craft bakers are in majority. According to its size, the bakery sector as a whole can be supposed to be one of the most distinct sectors of the food industry. However, this sector is getting maturity and showing signs of maturity, showing the fact in 2005 sales remained sluggish. Within the bakery sector, increased competition, in combination with evolving expectations of the consumer, particularly regarding convenience and health, has continued to effect trend of market. Consumers of today are expecting improvements and developments in manufactured product. Most important characteristic specifications of products include a longer shelf life, a fresh appearance, convenience tastiness, crunchiness, healthiness and, of course, a lower price. In baking industry, ingredients work in collaboration to obtain the desired texture and structure of bakery products (Abdullah, 2008).

In a mixture form the egg usually has one of two the functions. Beaten egg albumin is utilized, like baking powder, to make the dough an airy and light in texture. This property of egg white is due to its lecithin contents. When the egg was beaten, lecithin is a protein which encircles the peripheries of the air bubbles formed and so protects them from bursting during baking process. Lecithin acts as a binding agent in unbeaten whole eggs, in this way it holds the cake components together. In addition to the above properties eggs can be utilized as moisteners, emulsifiers and nutritionally, as a source of all essential amino acids and fat. For the Mallard reaction egg acts as a source of Protein when it is used as a glaze during processing. In various parts of the world cake definition is slightly different but most importantly the term refers to the food products which are characterized by compositions based on flour (wheat), eggs (whole), sugar and other liquids like milk, to which oil or fat might be added. Added liquids level is such that rather than forming dough a batter with low-viscosity is formed. The major difference between bread and cake is that the latter is most commonly and easily baked in a pan, mold or tin in order to form a food product of desired shape. Before baking, batter requires minimal processing (Cauvain, 2003).

In cake production eggs perform different kinds of functions, providing volume to the product, tenderness, structure and some nutritional qualities to the product. They have high protein contents and can have ability to form firm and complex networks with gluten due to their binding ability. Due to their whipping property and forming stable foams, they participate in the development of cake structure and volume. The egg proteins are denatured upon heating, in this way they help in stabilizing and setting the structure of product crumb. The yolk portion of an egg contains high lecithin and lipid contents which impart a tenderizing and emulsifying effect to the product. Eggs help in stabilizing the emulsion, retaining gas produced by the leaveners and preventing coalescence of air cell in the batter, resulting in desirable texture and fine crumb grain. Eggs also give little but significant color and flavor (from the yolk portion) and enrich nutritional value of cake (DesRochers et al., 2003).

Spray-drying technology is used in an extensive variety of processes ranging from manufacturing of food products to pharmaceuticals. Most freshly, spray-drying technology has been investigated to produce hollow micro-particles (Shabde et al., 2005). This chapter gives an approach to design a spraydrying chamber utilizing droplet size distribution model in combination with a rate-based description of the drying process. The design criterion of primary spray-drying chamber is the moisture content of the resulted particle. The prediction of the resulted properties of particle is compared to the data of experiment taken from a laboratory unit of spraydrying. The final results show that the design of final 
spray-drying chamber is affected by the flow rate of liquid feed, the temperature of inlet drying gas, and loss of heat (Shabde et al., 2005), (Shabde and Hoo, 2006).

Spray-drying technology is applied extensively in several industries like in the food industry; for instance, drying of a feed solution for generating specific products from the solution (Oakley, 2004), (Verdumren et al., 2001). Spray-drying process also has been utilized to manufacture solid or hollow micro-particles for various applications (e.g., composites of lightweight) (Shabde et al., 2005), (Wilcox and Berg, 1994).

Products related to bakery contribute one of the most utilized food products in the world. Amongst them, cakes are predominantly popular and connected in the mind of consumer with a delectable product with significant characteristics of organoleptic. The most important ingredients used in cake making are sugar, egg, fat and flour and each plays an excellent purposeful role in the eating and structural quality of the food product (Conforti, 2006). More particularly, a cake batter reveals a complicated foam and emulsion system which is processed by being heat set systems. Cake baking leads to an aerated and light structured product, as well as a large amount of volatile compound formation, which plays a significant role in formation of its characteristic flavor. These compounds are basically the final product of the maillard reaction, which takes place between the amino group of amino acids and reducing sugars, proteins and peptides. The raw material selection, as well as modification of the making method can change composition of cake structure and aroma. For instance, Pozo-Bayo et al. (2007) have suggested that by changing the formula of a cake and by replacing eggs with a leavening agent, significant modifications in some basic aroma compounds observed, while Paraskevopoulou and Kiosseoglou, (1997) reported that cakes formed from low cholesterol egg yolk concentrates had stiffer and harder textures compared to others.

An egg-shell like structure development in powder of skim milk has been studied in a stirring fluidized-bed dryer at different humidity and temperatures. The formed particles have amorphous cores and crystalline surfaces. The scanning electron microscope analysis reveals a thin layer of crystals of lactose at the nano-scale that is developed on powder surface while the XRD analysis reveals that cores of particle are still in amorphous form (eggshell form), so the properties related to surface have improved while the desirable properties of bulk (of good solubility) have been remained the same. During storage the final powders reveal better stability and flowability and less formation of cake by retaining dissolution times and good rehydration. Crystalline lactose nano-coating of milk powders and development in flowability and stability could be an excellent solution for industries related to dairy (Nima et al., 2011).

In the world, majority of eggs produced are sold in their raw form (shell form) for traditional consumers to use them in baking and other home recipes. Only $17 \%$ of eggs produced go into the products formed from egg in UK while in USA the value is nearer $30 \%$. Mostly the eggs required for the shell egg market are not surplus and they are of smaller size and downgraded eggs were used in egg products. Now a day, farmers have special contracts to produce eggs which can be used in further processing of egg and egg products and the damaged eggs cannot be utilized for this purpose. Most importantly there are three kinds of egg products: frozen, liquid, and dried products, with small scale markets for peeled eggs, hard-boiled eggs and hardboiled pickled eggs. Bakery and confectionery industries along with other industries are the major users of eggs to form egg products. In this way the processed whole egg can be used in many food processing industries and also in value added products. This process needs no pasteurization and subsequent drying it. While in America the Value-added products are often made with eggs that are pasteurized (Belyavin, 2003).

For some time it has been known that the products made from egg might have some members of the Salmonella group which can cause food poisoning, after the recent discovery of $S$. paratyphoid $\mathrm{B}$ in the egg product samples imported from UK the problem became more serious and alarming. These salmonellae before freezing or drying are destroyed through the process of pasteurization. This process is successful and requires careful control conditions. In present scenario the trend of pasteurization process to frozen whole egg in UK is negligible. The size of the tins in which the frozen product is to be delivered must be up to $20 \mathrm{~kg}$ which is suitable for $\mathrm{y}$-radiation treatment. A range of $0.3-0.5$ Mrad of $\mathrm{y}$-radiation will destroy salmonellae and cure the product quality (Brooks et al., 1959).

Our environment is full microorganisms and they found everywhere - in air, animals, soil, water and insects. Foods coming into contact with manure and 
dirt like eggs and the other produce grown with manure as a fertilizer have large number of microbes. So it is almost impossible to destroy all microorganisms, but precautions can be adopted to control the occurrence of harmful and dangerous microorganisms. Investigations found pseudomonads and coliforms on peripheries of egg processing equipments. For maintaining quality of egg proper handling and storage are important. Keeping eggs at room temperature or above $68 \mathrm{~F}$ may cause more quality lose in a day than in a week under refrigeration. Salmonella enteritidis has adapted itself to have survival in the hen's reproductive tract, in recent years. So occurrence of Salmonella enteritidis on some eggs shell was therefore not unexpected. An egg's inside was once supposed almost sterile. But, Salmonella enteritidis has been revealed inside a little number of eggs, in recent years. Surface cracks of egg shell could however enhance the chances of the microorganism inside the egg. Perishable foods such as fish, eggs, meat, milk and products of milk are highly susceptible to the growth of microorganism (Northcutt et al., 2004).

\section{REFERENCES}

Abdullah, M.Z. 2008. Quality evaluation of Bakery products. J. Comp. Vision Tech. Food Evaluation. 1(4): 481-482.

AEB (American Egg Board). 1999. Eggcyclopedia-the incredible edible egg. Park Ridge, IL.

Allen, R.M. and H.H.C. Bakker. 1994. Spray dryer control based on online particle size analysis. Chem. Engg. Research and Design. 72(2): 251-254.

Belyavin, C.G. 2003. Egg use in food industry. J. Food Sci. Nutr. 2: 2000-2004.

Bergquist, D.H. 1995. Egg Dehydration. In: Stadelman W.J. and O.J. Cotterill (Eds.). Egg Science and Technology. $4^{\text {th }}$ ed. Food Product Press. Binghamton, NY. 335-376.

Bertling, J., J. Blomer and R. Kummel. 2004. Hollow microspheres. Chem. Eng. Tech. 27(8): 829-837.

Brooks, J., R.S. Hannan, Belty and C. Hobs. 1959. Irradiation of eggs and eggs products. J. Applied Rad. Isotops. 6: 149-154.

Cauvian, S.P. 2003. Nature of cakes. J. Food Sci. Nutr. 2(2): 751-756.

Cheong, H., G. Jefferys and C. Mumford. 1969. A receding interface model for the drying of slurry droplets. Int. J. Heat and Mass Transfer. 13: 537-546.

Christofides, P.D. 2002. Model-based Control of Particulate Processes. Kluwer Academic Publishers, Norvell.

Conforti, F.D. 2006. Cake Manufacture. In: Hui, Y.H. (Ed.) Bakery Products: Science and Technology, Vol. 22. Ames: Blackwell Publishing. 393-410.
Cora, F., L. Belle and F.S. Gerog. 1947. Lifting power of dried whole egg when used in sponge cake. J. Food Sci. 12(4): 332-342.

Crowe, C.T. 1980. Modelling Spray-Air Contact in Spray Drying Systems. Hemisphere Publishing, New York. 2934.

DesRochers, J.L., K.D. Seitz and C.E. Walker. 2003. Chemistry of baking. J. Food Sci. Nutr. 2(8): 760-765.

Drusch, S. 2007. Sugar beet pectin: A novel emulsifying wall component for microencapsulation of lipophilic food ingredients by spray-drying. J. Food Hydrocoll. 21(7): 1223-1228.

Dziezak, J.D. 1988. Microencapsulation and Encapsulated Ingredients. Food Tech. 42(4): 136-151.

Farid, M. 2003. A new approach to modelling of single droplet drying. Chem. Engg. Sci. 58(13): 2985-2993.

Fletcher, D. and T. Langrish. 2003. Prospects for modelling and design of spray driers in the $21^{\text {st }}$ century. J. Drying Tech. 21: 197-215.

Ginsberg, H.N., W. Karnally, M. Siddiqyi, S. Holleran, A.R. Tall, S.C. Ramsey, R.J. Deckelbaum, W.S. Blaner and R. Ramakrishnan. 1994. A dose-response study of the effects of dietary cholesterol on fasting and postprandial lipid and lipoprotein metabolism in healthy young men. J. Arteriosclerosis and Thrombosis. 14: 576-586.

Guardiola, F., C. Rafael, M. Dave, R. Magda and B. Josep. 1995. Oxysterol formation in egg powder and relationship with other quality parameters. J. Agri. Food Chem. 43: 1903-1907.

Hazleton, J.L., J.L. DesRouchers, C.E. Walker and C. Wrigley. 2004. Cookis, biscuits and crackers, chemistry of manufacture. J. Grain Sci. 6(1): 307-312.

Herron, K.L. and M.L. Fernandez. 2004. Are the current dietary guidelines regarding egg consumption appropriate. J. Nutr. 134: 187-190.

Howell, W.H., D.J. McNamara, M.A. Tosca, B.T. Smith and J.A Gaines. 1997. Plasma lipid and lipoprotein responses to dietary fat and cholesterol: a meta-analysis. Amr. J. Clin. Nutr. 65: 1747-1764.

Katta, S. and W. Gauvin. 1976. Basic concepts of spray dryer design. AICHE J. 22(4): 713-724.

Keey, R.B. and Q.T. Pham. 1976. Behavior of spray driers with nozzle atomizers. J. Chem. Eng. 311: 516-521.

Kenyon, M.M. and R.J Anderson. 1988. Maltodextrin and lowdextrose equivalent corn syrup solids: production and technology for the flavor industry. Flavor Encapsulation. Washington, D.C. 7-12.

Kieviet, F. 1997. Modeling Quality in Spray Drying. P.hd. Thesis. Eindhoven University of Technology, The Netherlands.

Layman, D.K. and N.R. Rodriguez. 2009. Egg protein as a source of power, strength, and energy. J. Food Tech. 64(8): 67-71. 
Lechevalier, V., R. Jeantet, A. Arhaliass, J. Legrand and F. Nau. 2007. Egg white drying: Influence of industrial processing steps on protein structure and functionalities. J. Food Engg. 83: 404-413.

Maa, Y. and S.J. Prestrelski. 2000. Biopharmaceutical powders: Particle formation and formulation considerations. Current Pharma. Biotech. 1(3): 283-302.

Mahmoud A.G., J.H. Thomas and M. Aramouni. 2010. Comparative study of egg white protein and egg alternatives used in an food cake system. J. Food Processing and Preservation. 34(5): 411-425.

Masters, K. 1991. Spray Drying Handbook. John Wiley and Sons., $5^{\text {th }}$ ed. New York.

Mine, Y. 1995. Recent advances in the understanding of egg white protein functionality. Trends Food Sci. Tech. 6: 225232.

Morgan, J.N. and D.J. Armstrong. 1992. Quantification of cholesterol oxidation products in egg yolk powder spraydried with direct heating. J. Food Sci. 57: 43-45.

Narayan, P., D. Marchant and M.A. Wheatley. 2001. Optimization of spray drying by factorial design for production of hollow microspheres for ultrasound imaging. J. Biomedical Materials Research. 56(3): 333-341.

Nima, Y., A.G. Tim and Langrish. 2011. Egg shell like structures in dried milk powders. J. Food Research Int. 44(1): 39-45.

Northcutt, J.K., D.R. Jones, K.D. Ingram, A. Hinton and M.T. Musgrove. 2004. Airborne microorganisms in Commercial shell egg processing facilities. J. Poult. Sci. 3: 195-200.

Oakley, D. 2004. Spray dryer modeling in theory and practice. J. Drying Tech. 22(6): 1371-1402.

Obara, A., M. Obiedzinski and T. Katczok. 2006. The effect of water activity on cholesterol oxidation and freeze dried egg powder. J. Food Chemi. 95(2): 173-179.

Obón, J.M., M.R. Castellar, M. Alacid and J.A. FernándezLópez. 2009. Production of a red-purple food colorant from Opuntia stricta fruits by spray drying and its application in food model systems. J. Food Engg. 90: 471479.

Palencia, C., J. Nava, E. Herman, G. Rodr'ıguez-Jimenes and M. Garc'ia-Alvarado. 2002. Spray dryer dynamic modeling with a mechanistic model. J. Drying Tech. 20(3): 569-586.

Paraskevopoulou, A., and V. Kiosseoglou. 1997. Texture profile analysis of heat formed gels and cakes prepared with low cholesterol egg yolk concentrates. J. Food Sci. 62: 208-211.

Patel, R.P., M.P. Patel and A.M. Suthar. 2009. Spray drying technology: an overview. Ind. J. Food Sci. Tech. 2(10): 44-47.

Pozo-Bayon, M.A., A. Ruı'z-Rodrı'guez, K. Pernin and N. Cayot. 2007. Influence of eggs on the aroma composition of a sponge cake and on the aroma release in model studies on flavored sponge cakes. J. Agri. Food Chem. 55: 1418-1426.
Quigley, J.D. 2002. Effects of spray dried whole egg and boitin in calf milk replacer. J. Dairy Sci. 81(1):1 98-203.

Robert, M. and K. Gail. 1998. The performance of decolorized bovine plasma protein as a replacement for egg white in high ratio white cakes. J. Food Quality and Prefrence. 9(3): 135-138.

Ronald, C.D. 1997. Spray drying innovative use of an old process. J. Design Elements. 7: 97-113.

Schuck, P., A. Dolivet, S. Méjean, P. Zhu, E. Blanchard and R. Jeantet. 2009. Drying by desorption: a tool to determine spray drying parameters. J. Food Engg. 94: 199-204.

Shabde, V.S. and K.A. Hoo. 2006. Design and operation of a spray dryer for the manufacture of hollow microparticles. Industrial and Engg. Chem. Research. 96(4): 114-119.

Shabde, V.S., S.V. Emets, U. Mann, K.A. Hoo, N.N. Carlson and G.M. Gladysz. 2005. Modeling a hollow micro-particle production process. Comp. Chem. Engg. 29(11): 24202428.

Shabde, V.S., S.V. Emets, U. Mann, K.A. Hoo, N.N. Carlson and G.M. Gladysz. 2005. Modeling a hollow micro-particle production process. Comp. Chem. Engg. 29(11): 24202428.

Shahidi, F. and U.N. Wanasundara. 1995. Oxidative stability of encapsulated seal blubber oil. J. Flavor Tech. 610: 139151.

Shehab, S.K., N.M. Darwish and M.A. Sadek. 1978. Depletion of glucose in Egyptian egg white before dehydration. Nahrung Food. 22(1): 3-9.

Sheu, T.Y. and M. Rosenberg. 1995. Microencapsulation by spray drying in whey protein and carbohydrate wall systems. J. Food Sci. 60(1): 98-103.

Sirignano, W.A. 1999. Fluid dynamics and transport of droplets and sprays. $1^{\text {st }}$ ed. Cambridge University Press, Cambridge, UK.

Toledo, R.T. 1980. Fundamentals of Food Process Engineering. Westport: AVI. 370-372.

Vega-Mercado, H., M.M. Gongora-Nieto and G.V. BarbosaCanovas. 2001. Advances in dehydration of foods. J. Food Engg. 49(4): 271-289.

Verdumren, R., H. Straatsma, M. Verschuren, J. Haren, E. Smit, G. Bargeman and P. Jong. 2001. Modelling spray drying processes for dairy products. $1^{\text {st }}$ International Symposium on Spray Drying of Milk Products. 453-463.

Weggemans, R.M., P.L. Zock and M.B. Kata. 2001. Dietary cholesterol from eggs increases the ratio of total cholesterol to high-density lipoproteins cholesterol in humans: a meta-analysis. Amr. J. Clin. Nutr. 73: 855-891.

Wilcox, D. and M. Berg. 1994. Microsphere fabrication and applications: an overview. Material Research Society.

Zbicinski, I. and R. Zietara. , 2004. CFD model of countercurrent spray drying process. In 14th International Drying Symposium, volume A, pages 169-176. 